\title{
Parents under Lockdown: the Impacts of the COVID-19 Pandemic on Families
}

\author{
Elisabetta Biffi, Maria Benedetta Gambacorti-Passerini, Daniela \\ Bianchi, ${ }^{3,4}$
}

\begin{abstract}
This paper explores aspects of parenting during COVID-19 lockdown, analyzing the international literature and presenting a study conducted in Italy during the initial period of social isolation (March-May 2020). The pandemic has made childcare challenging for parents globally, compromising the well-being and mental health of caregivers themselves (Brooks et al., 2020), and creating a potentially highly vulnerable situation for children (Gromada, Richardson, Rees, 2020). The COVID-19 emergency and the restrictions it has entailed bear short- and long-term implications for families, including the potential impact of delaying implementation of the Sustainable Development Goals (United Nations, 2015) and increased risk of children witnessing or experiencing violence and abuse (End Violence Against Children, 2020). Given this background, we investigated the family ecosystem, exploring both individual and parental factors in parents' relationships with their children, during lockdown.
\end{abstract}

Keywords: parent-child relationship, COVID-19 lockdown, Italy, parenting support, violence against children.

\section{Abstract}

Il contributo intende esplorare alcuni aspetti della genitorialità durante il lockdown, attraverso un' analisi della letteratura internazionale e la presentazione di una ricerca condotta in Italia durante il periodo del primo confinamento (marzo-maggio 2020). L'arrivo

${ }^{1}$ Associate Professor in General and Social Pedagogy at the "Riccardo Massa" Department of Human Sciences for Education - University of Milano-Bicocca.

${ }^{2}$ Assistant Professor in General and Social Pedagogy at the "Riccardo Massa" Department of Human Sciences for Education - University of Milano-Bicocca.

${ }^{3}$ Research Assistant at the "Riccardo Massa" Department of Human Sciences for Education - University of Milano-Bicocca.

${ }^{4}$ The paper is the outcome of the joint work of the three Authors; however, parr. 2.3, and 2.4, and the Conclusions were drafted by Elisabetta Biffi; parr. 2, 2.1, and 2.2, by Maria Benedetta Gambacorti-Passerini; parr. 1, 1.1, and 1.2, by Daniela Bianchi (from now on, unless otherwise specified, footnotes are edited by this paper's Authors, Editor's Note). 
della pandemia ha reso l'assistenza all'infanzia una sfida difficile per i genitori a livello globale, compromettendo il benessere e la salute mentale degli stessi caregivers (Brooks et al., 2020) e creando una situazione potenzialmente vulnerabile per i bambini (Gromada, Richardson, Rees, 2020). La crisi provocata dal COVID-19 e le limitazioni che ha portato potrebbero avere implicazioni a breve e lungo termine per le famiglie, inclusi i potenziali effetti di una ritardata attuazione degli Obiettivi di Sviluppo Sostenibile (United Nations, 2015) e un maggior rischio che i bambini assistano o subiscano violenza e abusi (End Violence Against Children, 2020). Sulla base di queste premesse, il documento si concentra sull'indagine dell'ecosistema familiare, esplorando le dimensioni individuali e gli aspetti genitoriali nella relazione con i bambini durante il periodo di lockdown.

Parole chiave: relazione genitori-figli, lockdown da COVID-19, Italia, sostegno alla genitorialità, violenza all'infanzia.

\section{The COVID-19 pandemic; the international scenario}

On March 11, the World Health Organization declared COVID-19 a pandemic (WHO, 2020). In order to protect the health of the world's population, many countries implemented measures to contain the spread of COVID-19, including school closures, home isolation and community lockdown, all of which have secondary impacts on children and their families (Dulieu, Burgess, 2020).

The COVID-19 pandemic has not stopped at national borders. It has affected people regardless of their nationality, level of education, income, or gender. However, the same may not be said for its indirect consequences, which have hit the most vulnerable hardest (Schleicher, 2020).

\subsection{The impacts of the pandemic on families}

The restrictive measures required by the pandemic have exacerbated and accelerated existing social inequalities within and between countries, with job losses pushing many families further into poverty and school closures creating a wider educational divide, and impacting children's life opportunities, and their physical and mental health (Eurochild, 2020). Even prior to the COVID-19 pandemic, families had been described as undergoing «a global childcare crisis» (Samman et al., 2016, passim).

The advent of the public health emergency has made childcare an even greater challenge for parents globally, both in the short and longer 
term. In the current lockdown scenario, the measures adopted have often included the closure of childcare centers and schools. They have often also entailed restrictions on other childcare options: for example, grandparents may no longer be available to care for their grandchildren. This combination of closures of childcare services and restrictions leaves working parents in a difficult situation.

In this context, the well-being and mental health of parents themselves as caregivers are critical. Research on the COVID-19 emergency is still new, but early reports indicate that one in four home-isolated parents display mental ill-health symptoms compared with one in 20 non-isolated parents (Brooks et al., 2020). Families' everyday lives have been seriously affected, and the spaces and times underpinning the daily routines of parents and children have undergone radical changes. Furthermore, greater responsibility for children's education has fallen on the shoulders of families since the introduction of distance education methods (Bucholz et al., 2020), and this has given rise to new tensions and challenges.

In such a scenario, the caregivers' own well-being and mental health are critical factors (Brooks, 2020). Without adequate support, parents can become stressed, exhausted, and forced to make sacrifices in relation to their social life, education and employment. This creates an extremely challenging situation for parents and potentially a highly vulnerable one for children (Gromada, Richardson, Rees, 2020). While the long-term implications of the COVID-19 crisis for the mental health of either children or adults are yet unknown, there is reason to believe they may be substantial, including the potential longer-term effects of delayed implementation of the Sustainable Development Goals (United Nations, 2015).

\subsection{The impacts of the pandemic on children}

As warned by the United Nations, the economic consequences of the pandemic and the resulting threat of economic recession are seriously affecting hundreds of thousands of children around the world. While generally not among those directly affected by the COVID-19 pandemic, children are at risk of becoming the main victims both in the immediate future and over the medium and long term (United Nations, 2020). Their right to grow up healthy, to study, to live their childhood peacefully, and build the future they desire has become even more at 
risk. Away from school, deprived of opportunities to learn and develop their skills, for millions of children childhood is ending before it even begins.

The restrictive measures imposed to contain the pandemic are having and will continue to have dramatic indirect and hidden economic, social, and cultural consequences for the most vulnerable groups in the world's population, including children. As the main indirect victims of COVID-19, children are paying and will pay the highest price. Furthermore, it is clear that even within countries, the pandemic is bringing to the fore and exasperating the social inequalities that were already present in the population. Thus affecting, especially for children who were already in difficult situations, the opportunity to survive, be fed and receive protection, or participate in educational processes and learn. In a word, the opportunity to grow and develop (Save the Children, 2020).

COVID-19 lockdown is affecting children in multiple ways, including by threatening child safety. Confinement and protective measures carry a greater risk of children witnessing or experiencing violence and abuse. According to the Joint Leaders' statement, efforts to contain the coronavirus are exposing children, especially the most vulnerable, to an increased risk of violence (End Violence Against Children, 2020).

Furthermore, children's reliance on online distance learning platforms has also increased their risk of exposure to inappropriate content and online predators (United Nations, 2020). According to the recently published Global status report on preventing violence against children 2020 (WHO, 2020) $)^{5}$ global responses to violence against children in times of COVID-19 have focused on how governments and communities can enhance families' ability to cope with the stress of confinement and anxiety about the future.

There has also been a joint effort to provide all families with concrete advice on how to enhance positive relationships between parents and children (UNESCO, WHO, UNICEF, End Violence Against Children, 2020). Such measures require a systematic approach to supporting parents, promoting positive parenting behaviors, and developing forms of educational support for parents.

5 Cf. https://www.who.int/teams/social-determinants-of-health/violence-prevention/global-status-report-on-violence-against-children-2020 (last access: 17.4.21). 


\section{A study of parenting during COVID-19 lockdown, in Italy}

Within this framework, we set out here to give voice to parents who have experienced lockdown conditions, exploring selected aspects of parenting, and particularly the parent-child relationship, during the social isolation period. Understanding the impact that a prolonged period of confinement has had on the family environment can inform interventions promoting parenting practices that are respectful and mindful of the rights of children and adolescents.

Hence, we present a study conducted with Italian parents between April and May 2020. The study was conducted by the Italian research unit at the University of Milano-Bicocca, under the auspices of the Erasmus+ KA2 DEPCIP (Digitized Education Of Parents For Children Protection) Project ${ }^{6}$, whose aim is to develop training interventions for parents that promote children's rights and prevent violence, across five partner countries (Greece, Italy, Lithuania, Spain, and Turkey).

To this end, the project includes research focused on listening to the voices of parents, and advancing understanding of the family ecosystem by exploring individual factors (emotional states, availability of resources, support received, well-being and vulnerability), spatial factors (transformation of places, attribution of new meanings) and parental factors in the parent-child relationship (communicating the health emergency, managing difficult situations, triggers that make parents "lose their patience").

\subsection{Method and research sample}

We adopted a phenomenological approach, within a qualitative research framework (Van Manen, 1990). The research instruments were quali-quantitative guided interviews administered via Computer Assisted Web Interview (CAWI) technology and in-depth qualitative interviews, in keeping with our exploratory, mixed-method research design (Teddlie, Tasshakori, 2006). Participants were recruited by means of convenience sampling (Emerson, 2015) and the following inclusion criteria were applied: having a child under the age of 18; having spent

${ }^{6}$ DEPCIP Project (2019-1-TR01-K204-077577); Project web-link: http://depcip. $\mathrm{com} /$ (last access: 17.4.21). 
at least four weeks in social isolation; being physically located in Italy during lockdown.

The data was collected over approximately two weeks between April and May 2020. The questionnaire was sent out via email, social networks, and instant messaging platforms, eliciting spontaneous responses from a large number of parents. The convenience sample consisted of about a thousand parents from the countries involved in the project. The wellknown methodological limitations of conducting surveys with convenience samples emerged clearly from an analysis of the participants' demographic characteristics, especially in the domains of gender, region of residence, educational background, occupational status, and housing situation.

More specifically, in Italy the research was conducted with about 400 parents, of whom over $90 \%$ were mothers (mean age 41.9 years, children's mean age 8.2 years) living in Lombardy, the region most affected by the pandemic in the entire country. A further key characteristic of the sample was its high level of education $(57 \%$ of parents had at least a university degree).

Participants' employment status was also somewhat homogeneous, with office workers making up $69 \%$ of the total sample and freelance or self-employed workers only $16 \%$; a further $7 \%$ were unemployed. With regard to participants' work situation during the COVID-19 emergency, some $46 \%$ were working from home, and $18 \%$ were attending their workplace as before, while $36 \%$ stated that they were currently not working. With regard to housing: the majority lived in comfortable homes $(63 \%$ lived in a three-room or four-room apartment; $22 \%$ in a detached house); only $6.5 \%$ lived in a one-room or two-room apartment. Furthermore, $80 \%$ of parents were married or cohabiting, while only $10 \%$ reported being separated or divorced.

The sample was therefore composed of mothers with a high level of education, in third-party employment, who during the COVID-19 emergency had the opportunity to work from home and lived in comfortable dwellings. The outcomes of the research were therefore affected by this starting situation, which does not feature particular difficulties, as might be the case, for example, for parents who had lost their jobs, lived in less comfortable housing, or were single parents. For this reason, the sample cannot be considered representative of the broader population and the results should be considered in terms of transferability rather than generalizability.

In future research, it would be of value to reach out to parents with a more disadvantageous socio-economic situation, perhaps by using dif- 
ferent sampling methods (such as randomized sampling) and also different methods of administering the research instruments, which would make it accessible to all types of respondent. Indeed, the literature indicates that CAWI methods generate a low response rate in groups with limited resources (Christensen, 2013).

However, for the purposes of this research, we chose convenience sampling because it offered other advantages, including the opportunity to elicit a rapid response (given the emergency situation and the need to collect the data within a very short time-frame) and the opportunity to compare parent-child relationships among parents from a similar background. Indeed, the results of the survey are of value precisely because the parents interviewed belong to a group that might be defined as competent informants who were not affected by major socio-economic disadvantages.

\subsection{Parents' emotions as expressed through metaphors}

The study investigated the emotions experienced by parents, also through the use of metaphors that could somehow give voice to emotions and feelings elicited by lockdown that they had not yet been able to directly express, or process.

Parents were asked the following question: "If you were to describe in a sentence or metaphor what it means to be a parent during this time of emergency, what would you write?". A qualitative analysis was conducted on the interview texts. Three researchers worked independently on the responses provided by the parents and then compared, discussed and progressively agreed the thematic categories they had identified in the data, based on the images and metaphors used by the parents. An initial list of categories was then presented to and discussed with the entire research team. The identified categories in order of prevalence were: Strength/Inventiveness/Positivity (N 86); Fatigue/Exhaustion/Worry (N 63); Support and Acceptance (N 54); Responsibility/Commitment (N 52); Multitasking (N 50); Patience/Resistance (N 38); 24-bour parenting (N 27); Armor (N 10); Oxymoron (N 10). Some cross-cutting categories were also identified, including: Images (N 41); Sea (N 13); Mountain (N 4); Animals (N 6); Superbero (N 5).

The questionnaire data showed that the parents, while declaring that they felt ready to cope with the ongoing emergency (about $70 \%$ of the interviewees), had experienced strongly conflicting emotions during lockdown, alternating feelings of worry and anxiety with moments de- 
scribed as unexpectedly positive and calm in the relationship with their children. Based on the parents' responses, two opposite poles were identified: one that we might define as negative (which comprehends the parents' worries, anxieties, and difficulties) and one that is more positive (encompassing feelings of optimism, joy and hope).

Indeed, lockdown caused parents to experience swinging emotions, and conflicting feelings, which sometimes escaped their control. The images and metaphors that the interviewees associated with being parents under lockdown reflected the need to adapt to and to become more comfortable with these contrasting emotions and themes in their everyday experience. Parents who stated that they did not feel ready to cope with the lockdown also reported that they felt unable to transmit security and peace of mind to their children. The theme of armor, of wearing a mask with their children often recurred: parents can believe that they should only communicate tranquility and normality to their children. Some parents felt inadequate during the isolation period.

On the contrary, welcoming and displaying their negative emotions and making them part of their relationship with their children would be challenging but also a useful strategy, because in this way the children would learn how to engage with their own negative emotions by seeing how their parents deal with theirs. This concept could inform new interventions for parents, designed to help them tolerate the discomfort and ambivalence of undergoing contrasting experiences and to engage with negative feelings as well as positive ones, allowing both themselves and their children (United Nations, 2020) to display negative emotions, with a view to identifying and dealing with them.

\subsection{The impact of COVID-19 on everyday family routines}

In general, interviewees had found it challenging to quickly reorganize their daily routine, coping with completely new circumstances, such as smart working, and distance learning, not to mention the need to strike a new balance in the dynamics between them and their children. These challenges became evident when parents were asked to reflect on what factor most caused them to lose patience with their children, on the reactions that ensued, and on the strategies they had ultimately deployed in response to these issues.

The unexpected social isolation experience led to a large increase in the kinds of situations that made parents lose their patience, leading 
them to experience complex emotions and to work on their ability to manage the most difficult situations. Understanding the situations that led to losing control was the first step required to avoid exploding: parents needed to identify their "boiling point", and work out how not to reach it so as not to "explode".

Thematic analysis (Braun, \& Clarke, 2006) led to the identification of three salient dimensions of the parent-child relationship: managing everyday life, relating to the world of the child, and relating to the child. About two out of three parents reported that managing daily routines was a situation that typically made them lose patience with their children. A routine is made up of habits, or rather rituals, which, due to being performed every day, elicit a sense of safety and tranquility. Given that lockdown upset previous patterns of everyday life, parents were obliged to invent a new routine, with no little difficulty. The habits and small everyday rituals they had previously consolidated with their children now failed, eliciting a strong sense of disorientation and threatening the parents' own sense of security. At the same time, the children suffered even more from this change in routine. The lack of certainty made them more worried and apprehensive, further increasing the burden on their parents.

The thematic analysis suggested that the most difficult moments for parents with their children, in relation to the management of everyday life, concerned both the management of spaces and times and the children's reactions to changed routines. The data suggested that online schooling/homework were among the situations that most made parents lose patience during lockdown. Suffice it to think of the challenges involved in ensuring adequate time and space to all family members, in a situation where parents were often working from home while their children were simultaneously following distance learning programs.

It was difficult for parents to strike a balance between the demands of their professional and personal lives, on top of housework. Regarding the behavior on the part of their children that most frequently made them lose their temper, most parents mentioned their children not obeying or cooperating, or being messy and making noise, often while their parents were required to work.

With regard to the second thematic area concerning parents' relationship with the world of the child, the two subcategories that emerged most strongly were: quarrels among children and device management. By devices we mean PCs, tablets, mobile phones, video games, and TVs. Even more markedly during lockdown, compared to the past, these technological devices took on a new meaning, because they were the only available 
channels of communication with the outside world and with the children' schools. Hence, they were not only used for entertainment, or to play, but also as invaluable tools for maintaining contact with the children's peers. One difficulty cited by the parents we interviewed concerned the management of electronic devices. On the one hand, in fact, the lockdown prompted over-investment in these technologies; on the other hand, while limiting their use had represented, prior to the lockdown period, an effective punishment strategy, it now acquired an even more punitive valence.

This data is even more significant in light of recent news events - some tragic in nature - concerning children and the use of technologies. The management of technological devices and social media in general has become very difficult for parents, especially during periods of social isolation, when - while the space of the physical world is contracting - children seek to establish a space for themselves in the virtual world, which is also the only way that they can socialize outside their own home. In recent weeks, news stories have provided examples of the dangers associated with social media and, at the same time, raised multiple questions about the correct use of technological instruments, who should manage them and, above all, how to prepare children to make mindful use of them. Giving a smartphone to a child does not just entail giving him an object, but rather the opportunity to join an environment, the digital one. For this reason, when a parent decides to put a technological device into the hands of a child, supervision and guidance are essential. The fact that children easily master these tools from a technical point of view does not mean that they also have the maturity required to understand the meaning of what they are doing.

As regards the last thematic area identified, the parent-child relationship, a key outcome is that many parents reported that they lost patience when felt that their children were not listening to them, as well as when they were unable to understand their children. These two responses suggest that on the one hand, parents do not feel heard and understood by their children while on the other, parents themselves seem unable to understand their children. This brings to light the mutual need of parents and children to be heard and understood, especially at extraordinarily challenging times.

\subsection{The parent-child relationship}

From a pedagogical point of view, it is of interest to study how best to intervene when critical situations arise. In general, the parents we inter- 
viewed reported that they had been more permissive than normal during lockdown. However, analysis of the actual practices implemented with children, shows that parental corrective action (what we conventionally refer to as punishment) took a range of different forms: most of the interviewees reproved their children by raising their voices $(83.8 \%)$, or by turning off electronic devices $(79.7 \%)$. Some parents took away their children's favorite games/toys $(43.2 \%)$, others forced them to carry out a particular activity $(38 \%)$ or to do household chores $(34.3 \%)$. Some parents opted to stop communicating with their children, by not talking to them $(30.3 \%)$ or locking them in their bedrooms $(11.4 \%)$. The data also shows that $29 \%$ of parents resorted to physical punishment such as slapping or spanking, occasionally $(27.4 \%)$ or habitually $(1.6 \%)$.

Similar outcomes were found in the most recent Italian study on the use of physical punishment (Save the Children, 2012), confirming that these practices exist and continue to be present in the culture. At the same time, this data should not be read as an index of the proportion of violent parents, but rather as a measure of parents' ability to recognize their own use of punishment, and their awareness that certain practices are not so legitimate.

This interpretation is borne out by the finding that $18 \%$ of parents said they felt they had behaved violently towards their children during lockdown. This helps to put the previous outcome into context: physical punishment is still widespread, but is also seen as lacking in legitimacy. It is often associated with reaching a boiling point, that is to say, with relatively extreme situations in which parents feel that they are losing control, when "your brain disconnects and you raise your hand without thinking"'.

The issue, therefore, is not one of violent parents, but of the risk of violence that is inevitably always present whenever there is an educational relationship. This dynamic should not be understood as an act but as a process (Biffi, Macinai, 2020) that is closely related to multiple dimensions. Adults bear full responsibility for managing particular situations and the overall context, but they also detain more power than do their children. The adults in our society almost invariably enjoy greater power to make decisions. Involving minors in decision-making processes always requires the mediation of adults whose role is to protect children and ensure that their rights are respected (Biffi, 2020). There is also a dy-

${ }^{7}$ The words used by one of the parents interviewed. 
namic of need (Miller, 1979, Eng. transl. 1995; 1980, Eng. transl. 1983); it is clear that children are generally needier than adults, and that, during lockdown, they needed adults to help them in areas in which they had previously been more independent.

Parents were also asked what they did when they lost their tempers and over-reacted. Four different strategies were reported: many parents responded by trying to calm down, by moving away from their children or the particular situation, or even just breathing more deeply. Of course, under lockdown this was even more difficult than normal, because the space available for moving away was limited: hence, it was very difficult for some parents to detach themselves from certain family dynamics.

Another method deployed by parents was choosing to do something else with their children, proposing a new activity as a means of bypassing the problematic situation. Others reported communicating with their children, and speaking with them about what had happened. Finally, some parents reported sharing the critical incident with other people, whether a partner, their own parents or other family members (although remotely, via text messages, or phone calls).

\section{Conclusions}

A key question informed by the principles underpinning the present research Project, which include the notion that children can and should live in a way that is respectful of their dignity, concerns how best to intervene in the face of critical situations and responses that parents themselves may view as inappropriate.

The goal of the DEPCIP Project is precisely to develop training interventions for parents to prevent violence against children and promote children's rights and the opportunity for children to grow up in environments that respect their dignity. In this regard, international research has focused on three broad strategies (UNESCO, WHO, UNICEF, End Violence Against Children, 2020). The first is the training of individual subjects (adults and minors) with the aim of enhancing individual competence, including the ability of the individual child to recognize what is legitimate for him/herself and what it means to respect oneself and others. The second is the implementation of integrated prevention strategies within educational services and institutions, while the third consists of community-wide awareness-raising interventions aimed at eliminating the root causes of violence. 
The work that is to be done is complex (Biffi, Montà, 2020), in that it involves revisiting everyday micro educational practices (Bertolini, 1993) and seeking out ways of helping parents to access the resources available to them and avoid feeling isolated. This may be accomplished by providing spaces of discussion where parents may share their experiences and learn to imagine other possible parenting strategies. A sharing not only with other parents, but also with experts. The key to success is not per se the presence of someone who can tell parents how to deal with certain situations, but rather the awareness that there are spaces where parents can share their doubts and work on developing alternative strategies, both independently and through exchanges with others.

Parents interviewed during lockdown expressed the need to draw on all available resources to re-orient themselves within a generally disorienting situation. Some of the strategies that emerged from their feedback are summarized in the document Parents in lockdown: Ideas for not feeling trapped ${ }^{B}$, whose purpose is to offer parents practical suggestions for navigating these complex times.

By detailing the thoughts of the parents who participated in the study and exploring key issues that emerged, this document is intended to stimulate discussion and reflection on what it means to be parents during lockdowns, how best to communicate with children, how to reorganize everyday life and reconcile the commitments of different family members in challenging circumstances, such as the home becoming very crowded, and suddenly having to fulfill the additional functions of school, gym, and workplace. Parents expressed difficulty with tolerating uncomfortable emotions and urgently require support enabling them to engage with their discomfort with certain situations and emotions.

Parents should not view this discomfort as something to hide, devoting their energies to creating the perception in their children that the world around them is perfect. Rather they should take it as a pretext to work with their children on tolerating emotional turmoil and showing them, by their own example, which some situations are uncomfortable to go through. Furthermore, getting parents to share their thoughts served to make it clear that there are things that make parents "blowing up", but that these things happen to other parents also and are not exceptional events.

${ }^{8}$ The document can be consulted and downloaded at the following link: http://depcip.com/index/haber/68/parents-in-lockdown (last access: 17.4.21). 
The pathway forwards is long indeed, but it is crucial to begin sowing a small critical seed with respect to the use of punishment, helping parents to accept that mistakes can be sometimes made, but to become aware that by taking responsibility for error they have the opportunity to turn it into a valuable parenting resource.

\section{References}

Bertolini P. (1993): Ragazzi diffcili:pedagogia interpretativa e linee di intervento. Scandicci (Fi): La Nuova Italia.

Biffi E. (2020): Il rovescio della trama educativa. L'infanzia tra intimità e violenza. Milano: FrancoAngeli.

Biffi E., Macinai E. (2020): Ombre e ferite dell'educazione. Violenza e maltrattamento ai minorenni (http://ojs.francoangeli.it/_omp/index.php/oa/catalog/ book/454; last access: 31.12.20).

Biffi E., Montà C. (2020): When Violence is at the Border of the Visible: The Violence of the Smallest Gestures. RIEF-Rivista Italiana di Educazione Familiare, n. 1, pp. 43-58.

Braun V., Clarke V. (2006): Using Thematic Analysis in Psychology. Qualitative Research in Psychology, n. 3, pp. 77-101.

Brooks S.K., et al. (2020): The Psychological Impact of Quarantine and How to Reduce It: Rapid Review of the Evidence. The Lancet, n. 395, pp. $912-920$ (https://www.thelancet.com/pdfs/journals/lancet/PIIS01406736\%2820\%2930460-8.pdf; last access: 31.12.20).

Bucholz B.A., DeHart J., Moorman G. (2020): Digital Citizenship during a Global Pandemic: Moving Beyond Digital Literacy, Journal of Adolescent $\mathcal{E}$ Adult Literacy, 64(1), pp. 11-17.

Christensen, L. (2013): The Role of Web Interviews as Part of a National Travel Survey. In J. Zmud, M. Lee-Gosselin, M. Munizaga, J.A. Carrasco (eds.): Transport Survey Methods - Best Practice for Decision Making. Emerald Group Publishing, pp. 115-153.

Dulieu N., Burgess M. (2020): The Hidden Impact of COVID-19 on Child Rights. London: Save the Children International (https://resourcecentre.savethechildren.net/node/18174/pdf/the_hidden_impact_of_covid-19_on_ child_rights.pdf; last access: 31.12.20).

Emerson R. (2015): Convenience Sampling, Random Sampling, and Snowball Sampling: How Does Sampling Affect the Validity of Research? Journal of Visual Impairment and Blindness, 109(2), pp. 164-168.

End Violence Against Children (2020): Leaders' Statement. Violence against Children: A Hidden Crisis of the COVID-19 Pandemic (https://www.who. int/docs/default-source/coronaviruse/ending-violence-in-a-time-of-covid19---join-statement.pdf?sfvrsn=1cbd99f0_2; last access: 31.12 .20 ). 
Eurochild (2020): Growing up in Lockdown: Europe's Children in the Age of COVID-19. Brussels: Eurochild (https://eurochild.org/uploads/2020/12/2020Eurochild-Semester-Report.pdf; last access: 31.12.20).

Gromada A., Richardson D., Rees G. (2020): Childcare in a Global Crisis. The Impact of COVID-19 on Work and Family Life. Innocenti Research Briefs, 2020(18). Florence: UNICEF Office of Research-Innocenti (https://www. unicef-irc.org/publications/1109-childcare-in-a-global-crisis-the-impactof-covid-19-on-work-and-family-life.html; last access: 31.12.20).

Miller A. (1979): The Drama of Being a Child: The Search for the True Self. Eng. Transl. London: Virago, 1995.

Miller A. (1980): For Your Own Good: Hidden Cruelty in Child-Rearing and the Roots of Violence. Eng. Transl. New York: Farrar Straus Giroux, 1983.

Samman E., Melamed C., Jones N., Bhatkal T. (2016): Women's Work. Mothers, Children and the Global Childcare Crisis. London: Overseas Development Institute (https://www.odi.org/sites/odi.org.uk/files/odi-assets/publications-opinion-files/10333.pdf; last access: 31.12.20).

Save the Children (2012): I metodi educativi e il ricorso a punizioni fisiche. Vissuto e opinioni di genitori e figli (http://images.savethechildren.it/f/download/ ri/ricercaipsosamaniferme.pdf; last access: 31.12.20).

Save the Children (2020): Proteggiamo i bambini. Whathever it takes. L'impatto della pandemia sui bambini e sugli adolescenti in Italia e nel mondo (https:// www.savethechildren.it/cosa-facciamo/pubblicazioni/proteggiamo-i-bambini-whatever-it-takes; last access: 31.12.20).

Schleicher A. (2020): The Impact of COVID-19 on Education. Insights from Education at a Glance 2020. Paris: OECD (https://www.oecd.org/education/ the-impact-of-covid-19-on-education-insights-education-at-a-glance-2020. pdf; last access: 31.12.20).

Teddlie C., Tasshakori A. (2006): A General Typology of Research Designs featuring Mixed Methods. Research in the Schools, 13(1), pp. 12-28.

UNESCO, WHO, UNICEF, End Violence Against Children (2020): Global Status Report on Preventing Violence against Children (https://www.who. int/publications/i/item/9789240004191; last access: 31.12.20).

United Nations (2015): Transforming our World: the 2030 Agenda for Sustainable Development (https://sustainabledevelopment.un.org/post2015/transformingourworld/publication, last access: 31.12.20).

United Nations (2020): Policy Brief: The Impact of COVID-19 on Children (https://www.un.org/sites/un2.un.org/files/policy_brief_on_covid_impact_on_children_16_april_2020.pdf; last access: 31.12.20).

Van Manen M. (1990): Researching Lived Experience. Human Sciences for an Action Sensitive Pedagogy. Albany (NY): Suny Press.

WHO (2020): WHO Director-General's Opening Remarks at the Media Briefing on COVID-19 (https://www.who.int/director-general/speeches/detail/ who-director-general-s-opening-remarks-at-the-media-briefing-on-covid19---11-march-2020; last access: 31.12.20). 